\title{
Social Media Addiction Disorder
}

\author{
Rudrajit Paul
}

Bengal Physician Journal (2019): 10.5005/jp-journals-10070-6115

\section{INTRODUCTION}

Internet use has become an integral part of life of the modern man. While specific demographic groups like the millennials are avid users of internet, no age or gender group is exempted. Among the various uses of internet, social media is the most popular. There are various social media platforms like Facebook, WhatsApp, WeChat, Viber, Snapchat, Twitter, Instagram, and Reddit (just to name a few). These networking media are available either as android app or through Web browser platforms. These various platforms allow sharing of content like photo, video, files, and messages. And there are also other hugely popular social media platforms related to online multiplayer gaming.

As social media is becoming a force to reckon with, there is also increasing awareness of its effect on individual and mass psychology. While there are countless newspaper articles and op-eds about the effect of social media on human behavior, such sensational journalistic articles are not always based on evidence. The author of this article is interested in academic research data only. The subsequent discussion about social media addiction will, thus, be based solely on hitherto published scholarly articles and case reports.

\section{Extent of the Problem}

Internet addiction or social media addiction is still not officially recognized as a disease in the sense that it is still not included in the official Diagnostic and Statistical Manual of the American Psychiatric Association (DSM). ${ }^{1}$ But analysis of behavior patterns has revealed tell-tale signs of addiction. ${ }^{1}$ This is similar to the behavior pattern observed with alcohol addiction or gambling (gambling addiction is now recognized as a medical disease in DSM-V). Thus, in addicted persons, there is compulsive-impulsive internet use, obsession with specific websites or apps, loss of normal life functions, alteration of normal biological functions like sleep, and intense craving if deprived of access to the internet. Over the years, this has been variously termed as "compulsive internet use,"'dysfunctional internet use," or "internet dependency." In the subsequent paragraphs, "Internet addiction" and "social media addiction" will be used interchangeably.

A 2005 study in a UK university found that more than $50 \%$ of students reported one to three symptoms of excessive internet use while $18 \%$ fulfilled diagnostic criteria for pathological internet use. ${ }^{2}$ In this UK study, it was also found that male students were more likely to be pathological internet users compared to females. Also, students enrolled in courses like engineering and computing were more likely to be pathological users, compared to other courses like law. ${ }^{2}$ In 2016, Chi et al. published a similar study from China. ${ }^{3}$ In this, around $15 \%$ of students were found to have internet addiction. ${ }^{3}$ Poor parent-child relationship and depression were found to be associated with Internet addiction. In a landmark study, Yu and Shek from Hong Kong found that among adolescents (median age 12-14
Department of Critical Care Medicine, Institute of Post Graduate Medical Education and Research and Seth Sukhlal Karnani Memorial Hospital, Kolkata, West Bengal, India

Corresponding Author: Rudrajit Paul, Department of Critical Care Medicine, Institute of Post Graduate Medical Education and Research and Seth Sukhlal Karnani Memorial Hospital, Kolkata, West Bengal, India, Phone: +91 9433824341, e-mail: r.paul.medicalcollege@gmail. com

How to cite this article: Paul R. Social Media Addiction Disorder. Bengal Physician Journal 2019;6(2):25-27.

Source of support: Nil

Conflict of interest: None

years), internet addiction was present in around $25 \% .{ }^{4}$ Again, males were more likely to be addicted to the internet and poor family functioning was a predictor of such addiction. ${ }^{4}$ However, the basic academic question is: How do we define "addiction?"

One of the problems with studies of social media or internet addiction is the choice of a suitable scale for measuring addiction. The first studies on this topic had only drug addiction as a reference. Thus, they tried to extrapolate the scales of drug addiction disorder to measure internet addiction. ' Later, the tests for gambling disorder (included in the DSM) were modified to assess internet addiction. Young's test is one example of the later. However, as extent of the problem became more widespread, a diagnostic questionnaire specific to pathological internet use was devised. Example of this is the 20-item internet addiction test (IAT). Another recent one is the scale used by Morahan-Martin and Schumacher, which is a 13-item scale. ${ }^{5}$ Both of these scales are widely used in research projects.

The all-pervasive phenomenon of social media may be new but Internet has been there for almost three decades now. Similarly, the addiction to internet also dates back to the early days of its popularity. As far back in 1997, a study done in South America among college students found that $13 \%$ of regular users showed signs of addiction. ${ }^{6}$ Some specific behaviors observed among social media addicts are the "disinhibition effect" (whereby a person would say or write or do something online that they would never do in real life) and disclosing intimate personal details. Another correlate of this behavior is low self-esteem. ${ }^{2}$ Lower self-esteem is found to be associated with more time spent online. However, it is still debatable whether low self-esteem is a cause or effect of internet addiction. While low self-esteem may force people to spend more time online, it is also hypothesized that excessive time spent online may cause problems in normal social interaction and thus, low self-esteem. ${ }^{2}$ A lot of people find it difficult to find friends in real life. For them, the social media becomes a safe haven free of normal social boundaries of class, race, gender, or physical appearance. ${ }^{2}$ This loneliness may be one of the reasons for social media addiction. But is it so simple an explanation or are there other confounding factors too? 
Internet addiction can lead to serious disruption of life. In a recent firsthand account, one 19-year-old boy has described how internet gaming addiction led to low grades in school and almost discontinuation of college education. ${ }^{7}$ Finally, he had to enroll in a residential detoxification program like a drug addiction disorder. ${ }^{7}$ This boy is of the opinion that parents should intervene early to prevent internet addiction in their children. In 2017, the BBC also reported on rising incidence of social media addiction. ${ }^{8}$ One problem with social media addiction is that it is still not recognized as a medical disorder. This means the affected persons would not get any insurance coverage. ${ }^{8}$ However, the number of persons seeking help for social media addiction is rising.

As research into internet or social media addiction is evolving, the very definition of time spent online is changing. With android apps, everyone is connected to the internet almost all the time. Thus, "time spent online" is no longer a valid measure to find the level of internet addiction because no one needs to "log on" to internet now. Also, a very recent addition to internet use is the online streaming services like Netflix, Amazon Prime, or Hulu, which everyone is getting hooked into. How will a researcher characterize Netflix binge watching vis-à-vis television watching? Will obsession about Netflix be considered as television addiction or internet addiction? Such questions are yet to be answered.

Besides the obvious effects on school performance and psychosocial development, one other important effect of internet addiction is cyberbullying. ${ }^{9}$ Bullying online is defined as "an aggressive, intentional act carried out by a group or individual, using electronic forms of contact, repeatedly and over time against a victim who cannot easily defend him- or herself" (quoted from Smith et al., p. 376). ${ }^{10}$ This is major problem, especially for adolescents. Good parental supervision is essential to curb this menace. ${ }^{9}$

There are many alarming stories about cyberbullying. In one particularly gruesome incident, a 13-year-old girl was teased in a Myspace account repeatedly. She was already susceptible to depression. When her cyber stalker declared in a public message that the world would be better without her, she killed herself. ${ }^{11}$

\section{Indian SCEnaRIo}

As the use of social media in India is rising, the incidence of Internet addiction is also on the rise. There are very few academic studies on this topic from India. In a 2018 study from Karnataka involving university undergraduate students, $10 \%$ of engineering students were found to have moderate internet addiction. ${ }^{12}$ In similar other Indian studies, the prevalence of internet addiction has been found to range between $7 \%$ and $15 \% .{ }^{12}$ Similar to the data from the United States and the UK, male Indian students were more likely to have Internet addiction. Depression and other psychological distress were important factors associated with internet addiction.

Another important study, done among undergraduate medical students in Western India, found that the prevalence of internet addiction was almost $20 \% .^{13}$ The psychological factors, as described previously (like loneliness, anxiety, and depression), were also found to have significant associations with internet addiction among medical students. ${ }^{13}$

In one interesting psychiatric case report, a 27-year-old woman in India was addicted to WhatsApp messaging and this was associated with the borderline personality disorder. ${ }^{14}$ This WhatsApp addiction led to familial discord, irritability, loss of sleep, and loss of friendship. ${ }^{14}$ The patient had a compulsive behavior to check WhatsApp messages, for which she would get up at night frequently. Also, while going to the washroom, she would take the phone with her. She was treated with fluoxetine, valproate, and psychotherapy. ${ }^{14}$ Such compulsive behavior in varying degrees is also reported elsewhere.

As scientists and doctors are becoming aware of the extent of the problem, a whole new branch of knowledge, called cyber psychology, has emerged. There are very good online journals on this subject and readers are encouraged to consult them for further updates. New terminologies are now being coined to describe the behavior patterns. One prime example is a behavior pattern called FOMO: fear of missing out. ${ }^{15}$ People are obsessed about new comments in their post in Facebook or number of likes in a picture because they do not want to fall behind other users. Almost $75 \%$ of smartphone users now check their status as soon as they wake up. ${ }^{15}$ In 2013, in the journal, Computers in Human Behavior, Przybylski et al. found that the FOMO phenomenon would cause serious disruption in driving, learning, and normal daily functions. ${ }^{16}$ The addicted users would continue to browse social media during university lectures, meals, sometimes in toilet, and before sleep. ${ }^{16}$ While FOMO was more common among males in younger subjects, for older Internet users, the rate of the FOMO-related behavior disorder was common in both genders. ${ }^{16}$

\section{Conclusion}

Internet and social media addiction is an emerging psychological disorder all over the world. Young children are particularly susceptible to this addiction. Males and people with psychological issues like low self-esteem or personality disorder are more likely to suffer from this addiction. One major problem with internet addiction is that there is no social taboo associated with it, like drugs, alcohol, or gambling, and thus, it often remains under the radar. Although still not recognized as a disease in the DSM manual, this phenomenon is causing disruption of normal life in a significant number of people. Just as a gambling-related behavior disorder has now been recognized as a medical disease, hopefully Internet addiction will also be recognized as a medical disorder in the near future. This will help in securing better funding for management of the condition.

One important use or misuse of social media in recent times in India is patients sending their reports to physicians via whatsapp or facebook messenger. In this way, they try to bypass the actual visit to the clinic. Should this practice be allowed? The author would like to know opinions of the readers. Please send your comments via e-mail.

\section{References}

1. Wallace P. Internet addiction disorder and youth. EMBO Rep 2014;15(1):12-16. DOI: 10.1002/embr.201338222.

2. Niemz K, Griffiths M, Banyard P. Prevalence of pathological internet use among university students and correlations with self-esteem, the general health questionnaire (GHQ), and disinhibition. Cyberpsychol Behav 2005;8(6):562-570. DOI: 10.1089/cpb.2005.8.562.

3. Chi X, Lin L, Zhang P. Internet addiction among college students in China: prevalence and psychosocial correlates. Cyberpsychol Behav Soc Netw 2016;19(9):567-573. DOI: 10.1089/cyber.2016.0234.

4. Yu L, Shek DT. Internet addiction in Hong Kong adolescents: a three-year longitudinal study. J Pediatr Adolesc Gynecol 2013; 26(3 Suppl):S10-S17. DOI: 10.1016/j.jpag.2013.03.010.

5. Morahan-Martin J, Schumacher P. Incidence and correlates of pathological internet use among college students. Comput Human Behav 2000;16(1):13-29. DOI: 10.1016/S0747-5632(99)00049-7. 
6. Scherer K. College life on-line: healthy and unhealthy internet use. J Coll Stud Dev 1997;38(6):655-665.

7. Transcript of Podcast. Gaming and Internet Addiction: Ryan's Story. [Cited 2019 Nov 28]. Available online from https://www. distractionpodcast.com/2016/08/29/gaming-internet-addictionryans-story/.

8. Dizik A. The addiction that's 'worse than alcohol or drug abuse'. BBC Worklife. [Cited 2019 Nov 27]. Available online from https://www. bbc.com/worklife/article/20170417-the-addiction-thats-worse-thanalcohol-or-drug-abuse.

9. Brighi A, Menin D, Skrzypiec G, et al. Young, bullying, and connected. Common pathways to cyberbullying and problematic internet use in adolescence. Front Psychol 2019;10:1467. DOI: 10.3389/ fpsyg.2019.01467.

10. Smith PK, Mahdavi J, Carvalho M, et al. Cyberbullying: its nature and impact in secondary school pupils. J Child Psychol Psychiatry 2008;49(4):376-385. DOI: 10.1111/j.1469-7610.2007.01846.x.

11. Ingham A. 7 Real Life Cyberbullying Horror Stories. Family Orbit Blog. [Cited 2019 Nov 28]. Available online from https://www.familyorbit. $\mathrm{com} / \mathrm{blog} /$ real-life-cyberbullying-horror-stories/.
12. Anand N, Jain PA, Prabhu S, et al. Internet use patterns, internet addiction, and psychological distress among engineering university students: a study from India. Indian J Psychol Med 2018;40(5):458-467. DOI: 10.4103/IJPSYM.IJPSYM_135_18.

13. Gedam SR, Ghosh S, Modi L, et al. Study of internet addiction: prevalence, pattern, and psychopathology among health professional undergraduates. Indian J Soc Psychiatry 2017;33(4): 305-311. DOI: 10.4103/ijsp.ijsp_70_16.

14. Faye AD, Gawande S, Tadke R, et al. WhatsApp addiction and borderline personality disorder: a new therapeutic challenge. Indian J Psychiatry 2016;58(2):235-237. DOI: 10.4103/0019-5545. 183790.

15. Rosen LD. Always On, All the Time: Are We Suffering From FoMO? Psychology Today. [Cited 2019 Nov 29]. Available online from https:// www.psychologytoday.com/intl/blog/rewired-the-psychologytechnology/201305/always-all-the-time-are-we-suffering-fomo.

16. Przybylski AK, Murayama K, DeHaan CR, et al. Motivational, emotional, and behavioral correlates of fear of missing out. Comput Human Behav 2013;29(4):1841-1848. DOI: 10.1016/j.chb.2013. 02.014 . 